Candidate of Sciences in Physical Education, Associate Professor, Department of Physical Education Smirnov $K$. Senior Lecturer, Department of Physical Education Cherevuchko 0. Senior Lecturer, Department of Physical Education National Technical University of Ukraine Igor Sikorsky Kyiv Polytechnic Institute

\title{
FEATURES OF TEACHING SWIMMING TECHNIQUES OF STUDENTS AT DIFFERENT STAGES OF TRAINING
}

In the statti of rozkrito special features of the technology of swimming of students-sailors at different stages of training. The statistic has seen the formulation of the technique of an athlete-swimming from the point of view of the dynamic dynamics, and it has been established that the complex process of sports training from swimming can be cleverly adapted to the period. It is emphasized that when swimming technology is introduced, it is necessary to use the lines, holding out which swimmers will take away the latest sports results.

Immediately before the start of classes in the pool with students was an introductory lecture, which focused on the impact of swimming on the human body, determined its health value, on different ways of swimming, including applied, rules of conduct in the pool.

Analysis of the training of outstanding swimmers of today in the vast majority of cases shows that for many years a diverse functional base was created, and only in its presence and with the achievement of optimal age to demonstrate higher achievements, the most powerful training reserves are realized. Strict adherence to the principles of sequence of increasing the training load is of great importance in the process of planning long-term training. In this case, training loads at all stages of training generally correspond to the functional capabilities of the athlete, which contributes to a systematic increase in the level of training.

Key words: swimming, training stages, students, physical training, technology.

Дакал Н. А., Смірнов К. М., Черевичко О. Г. Особливості навчання техніки плавання студентів на різних eтапах підготовки. B статті розкрито особливості навчання техніки плавання студентів-плавців на різних етапах підготовки. У статті розглянуто формування техніки спортсмена-плавия з точки зору вікової динаміки та встановлено, що багаторічний процес спортивних тренувань з плавання умовно можна поділити на періоди. Акцентовано, що при навчанні техніки плавання необхідно орієнтуватися на строки, протягом яких плавещь отримує найвищі спортивні результати.

Ключові слова: плавання, етапи підготовки, студенти, фізичне виховання, техніка.

Formulation of the problem. Based on the analysis of the literature, it is noticeable that the patterns of sports training in swimming at the present stage of sport development have received a deep comprehensive justification and development. It is also established that in the framework of sports competitions swimming is improved to the greatest extent and is one of the most popular and popular sports in Ukraine and abroad. The urgency of the topic is due to the fact that the number of medals won at major international competitions, this sport is second only to athletics.

Analysis of recent research and publications. In recent years, a number of studies have been conducted on certain aspects of solving this problem by means of physical education and sports. This is, first of all, the study of the basics of sport swimming, the problem of selection in the process of long-term training, recommendations for determining the special training of young swimmers-sprinters; pedagogical control in the training of young swimmers, etc. The analysis of pedagogical and sports literature shows that today there is some experience in physical education and sports [1]. The problem of determining the prospects of athletes-swimmers at different stages of training in modern conditions is sufficiently studied. stages of training.

The aim is to carry out a theoretical analysis of the problem of determining the prospects of athletes-swimmers at different

Presentation of the main research material. The analysis of sports literature and practice proves that today the average age of the winners of the largest international competitions for men is from 18 to 25 years. Such a long period allows a person to go from a beginner to a master of sports of international class, to reach the international level of competition, etc. [2].

Every year, the effectiveness of training swimmers is increasingly determined by the level of special knowledge. Interesting and practically valuable knowledge received at development of structure of competitive activity of swimmers; ways to optimize the system of control, management and modeling in the system of sports training; methods of development of special motor qualities of swimmers strength, endurance, speed, flexibility, coordination abilities; effective variants of sports equipment, methods of psychological training; optimal structure of long-term training, rational construction of the annual cycle, macro- and microcycles of sports training. Today, swimming has a huge scientific potential. There is a huge amount of scientific work in this field of sports science: the theory and methods of various types of training of swimmers, organization and methods of sports selection and orientation in swimming, research of physical development, anthropometric, morphofunctional, psychophysiological characteristics of swimmers of different qualifications and their relationship with the level sports achievements, etc. [5].

Starting from the first steps of a gifted swimmer in sport swimming, an experienced coach who wants to train a qualified 
athlete, it is necessary to rely on modern information of sports science, to carry out long-term planning. Thus, when drawing up a work plan for a year, stage or the entire period of long-term training, it is necessary to focus on the optimal age limits in which athletes get the highest results. Such guidelines are data on the age of the best athletes in the world.

The training of swimming used a simultaneous technique, which involved the simultaneous development of all methods of swimming, first with the elements, starting with hand movements, then mastering swimming in various easy ways, and then - all sports in full coordination. The large number of used swimming movements at the initial period of training allows everyone to choose the most convenient way of swimming. This approach can significantly reduce the time of learning the experience of swimming, even for students with disabilities.

Along with general developmental and special exercises, learned with students first on land and then in water, used in classes a large number of breathing exercises, including after swimming different segments [4]. This prevents overload, fatigue, and contributes to the effective restoration of functional systems of the body.

When studying this method was also provided by students to master the elements of applied swimming: side swimming, breaststroke, diving in length and depth, providing assistance to drowning, transportation of "tired" on the water and various objects, the use of improvised and auxiliary means, the basics of proper behavior in the water in the event of various extreme and difficult situations.

When compiling long-term training, it is necessary to focus on the period during which the swimmer receives the highest sports results. In swimming, the first great success women achieve in 4-6 years of regular training, men in 5-7 years. Women reach higher achievements in 8-10 years, and men in 10-12 years. At the same time, the highest growth rates of sports results are observed in the first two years of specialized training. Thus, with properly organized long-term training, according to many experts, the performance of the standard of master of sports by girls is 15 years old, boys - 17 years, compliance with the standard of master of sports international class girls - at age 18 , boys - at age 20 [3].

It is known that the path to high achievements in swimming for men begins at about 10 years, for women - 2-3 years earlier. This duration of training is typical for the vast majority of the strongest swimmers in the world and should be the basis for building a long-term training process. With rational planning of the training process, this period can be divided into five stages, each of which has strictly defined tasks, tools and methods, planning system, features of competitive practice, etc. (initial training; preliminary basic training; specialized basic training; maximum implementation of individual opportunities; preservation of higher achievements).

At the first three stages the tasks of children's and youth sports are solved. At the fourth stage of long-term training the tasks of sports of the highest achievements, ie achievement of the highest sports results are solved [1;3].

Interesting for our study is the statement that if in the 90's many swimmers at the highest level performed successfully for 10-15 years, now rarely anyone manages to stay at the level of higher achievements for more than 4-5 years, and a tumultuous sports career some world and Olympic champions are often completed within a year.

This once again focuses on the need to shift the period of maximum training loads and the most influential training methods and tools with the optimal age zone to achieve high sports results. In the process of long-term training, the organization of the training process should be provided, which would significantly complicate the training program from one stage or from one microcycle to another. Therefore, it should be noted to clearly identify a number of areas that should be followed by the intensification of the training process throughout the path of sports improvement [2].

Analysis of the training of outstanding swimmers of today in the vast majority of cases shows that for many years a diverse functional base was created, and only in its presence and with the achievement of optimal age to demonstrate higher achievements, the most powerful training reserves are realized [4]. Strict adherence to the principles of sequence of increasing the training load is of great importance in the process of planning long-term training. In this case, training loads at all stages of training generally correspond to the functional capabilities of the athlete, which contributes to a systematic increase in the level of training.

To build a long-term training is very important rational combination of work of different predominant orientation. When determining the dynamics of changes in the work of aerobic orientation in the total amount of training should be borne in mind that young athletes have a high adaptation to such work. With a significantly low level of sportsmanship, they are almost inferior to adult athletes in terms of relative aerobic capacity. In the course of many years of training, the limits of aerobic capacity and improving performance should be mainly associated with the improvement of other components of sportsmanship [1].

With age, the ability to successfully tolerate work increases, which requires the manifestation of maximum strength, endurance at work of an anaerobic nature, speed and strength. The highest ability to develop speed and power qualities and anaerobic work is observed in men aged 18-21 years, women - aged 16-17 years. Special speed and power capabilities in men can develop to the greatest extent at the age of 18-20 years, and in women - at the age of 16-20 years, etc. [2].

$\mathrm{N}$. Bulgakova [1] notes that the growth of world records is closely interrelated with the improvement, the evolution of training: with the development of training devices; with the improvement of swimming technique; with the increase in the volume of work on land, its division into general and special physical training; with growth of volume and intensity of training loadings, both in weekly, and in annual cycles of preparation; with the division of the training load according to the direction of physiological influence; with an increase in total body size; with the widespread introduction of non-traditional means in the training of swimmers.

Analysis of the work of leading experts shows the existence of dependence of the periodization of the training process in swimming with age characteristics of athletes, due to heterochrony of physical development, uneven psychofunctional and physical capabilities of young athletes depending on the specific age period and more.

According to studies by N. Bulgakova, L. Nabatnikova [1], conducted on the strongest young swimmers-champions (age groups 11-12, 13-14 and 15-16 years), showed a close relationship between sports achievements with features of physique and efficiency. Obviously, in anthropometric surveys of swimmers can not be limited to determining only the total size of the body. It is also necessary to take into account the peculiarities of the physique, the ratio of levers and proportions that are genetically 
determined and largely determine the hydrodynamic qualities of the swimmer. In particular, the most informative indicator is the proportions of the body.

From the point of view of age dynamics of formation of the sportsman-swimmer long-term process of sports trainings on swimming can be conditionally divided into the following periods [2].

The first stage is teaching children to swim. The experience of many educators convincingly shows that it is best to teach children to swim from the age of $5-6$, when they are not afraid of water and love to swim, games should play a leading role in learning.

The second stage - learning the technique of sports swimming. 7-8-year-old boys and girls who have mastered the movements in the water, similar to the elements of sports swimming, it is easy to teach swimming in the crawl, breaststroke, butterfly and backstroke. However, in children's sports schools, many coaches question the appropriateness of such teaching methods.

The third stage is the training of 9-10-year-old swimmers. It is known that girls and boys at this age differ little in their physical development. In both cases, there are similar indicators of strength, endurance, attention, but the muscular apparatus is easily stretched, well-improved complex coordination of movements, easy to learn speed exercises. At this stage of swimmer training, two main tasks are solved: 1) health promotion and physical development; 2) improving the technique of all methods of swimming.

The fourth stage is the training of 11-12-year-old swimmers. At this age, the growth of children is significantly accelerated. In most cases, girls begin to overtake boys in their physical development; and sometimes they are able to show higher results in swimming. Regular exercise contributes to a rapid and significant increase in muscle mass of young swimmers. The adaptability of their cardiovascular system to physical activity (especially speed) improves. Sports results are starting to grow rapidly.

The fifth stage is the training of 13-14-year-old swimmers. At the age of 13-14, a person's body length increases the fastest, especially if he does sports. However, the growth of the organism occurs more in length than in width. In particular, the development of internal organs and major muscle groups lags behind the growth of the skeleton. At the same age, the excitability of the nervous system as a whole increases.

At the present stage, innovation is one of the productive ways to improve the process of physical education, as it provides an opportunity to use a variety of tools and methods of physical training of students. It is worth noting that the problem of improving the process of physical education is due to many factors, and, unfortunately, one of the main ones is the deterioration of the health of students.

Therefore, the introduction of innovative technologies in the system of physical education, in particular, swimming is quite relevant. Because swimming is a unique sport, useful for both adults and children. Swimming can not only improve health, but also improve the appearance. It has a positive effect on the main indicators of physical development: height, weight, strengthening the cardiovascular and nervous systems, the development of the respiratory system and muscular system. Swimming is also an excellent means of prevention and correction of posture disorders, scoliosis, flat feet.

In addition, psychologists have found that swimming develops such personality traits as purposefulness, perseverance, independence, determination, courage, discipline, ability to cooperate in a team. That is why swimming has a positive effect not only on physical development, but also on the formation of his personality.

The sixth stage is the training of a young swimmer. It is assumed that at this stage the period of puberty will end. The rate of growth of the body in length decreases significantly, but begins an intensive increase in width, which with the judicious use of exercise, as a rule, is accompanied by the development of lagging in adolescence internal organs. All this creates quite favorable conditions for the development of strength and endurance of the swimmer, as well as to maintain the previously achieved level of agility, speed and flexibility.

The training time of high-class athletes should be reduced not due to forced training and coaching of the swimmer, but due to the improvement of methods of its training at each of these stages.

Conclusions. Thus, the generalization of theoretical aspects makes it possible to understand that in practice there are a large number of examples when a coach to some extent tries to force the sports training of young swimmers. Such training work can cause only a temporary flash in the dynamics of the swimmer's results, but it will never bring him to the top of modern skill. At forced training it is possible to achieve fast development of some motor qualities, and at the gifted sportsman even to form for a while excellent technique of swimming. However, lagging behind in the development of more inert autonomic functions can lead to disruption of all training of the athlete, and he will never show the results he could achieve if his training load increased not only systematically but also gradually over many years, etc.

\section{Literature}

1. Bulgakova N. Methods of long-term training of young swimmers: method. Recommendations / under the general editorship.M., 1989. - $50 \mathrm{~s}$.

2. Petrovich G. Features of training of swimmers at various stages of long-term training: Method. recommendations. I Minsk: RUE "Minsk. type. - project », 2002. 24 p.

3. Platonov V. Training of high-class swimmers. M .: FiS, 1985. $-256 \mathrm{p}$.

4. Sakhnovsky K. Swimming. K.: Health, 1986 .-- 72 p.

5. Tymchyk M. Physical education of older adolescents in the process of sports games in secondary schools // Modern educational process: essence and innovation potential Materials of the reporting scientific-practical conference. - Ivano-Frankivsk, NAIR. - 2013. - P. 437-440. 